\title{
How to Manage the Low-Risk Patient with Lower Respiratory Tract Infection?
}

\author{
Gérard Huchon \\ Université de Paris René-Descartes, Service de Pneumologie, Hôpital Ambroise Paré, Boulogne, France
}

In this issue of Respiration, Rovira et al. [1] report that clarithromycin alone was as efficient as clarithromycin in association with cefuroxime in the treatment of outpatients with community-acquired pneumonia (CAP) without risk factors for mortality or complicated courses. There are several limitations in that study: one third of the patients received antibiotics prior to inclusion, the number of patients included was small, and the trial was open. However, studies on the same topics have shown that the success rate is high with a large variety of antibiotics in low-risk outpatients with CAP and that using an association of antibiotics or a large spectrum antibiotic adds no or little to the success rate. It is important to consider this issue in view of the difficulties in diagnosing pneumonia and in identifying the pathogens in a community setting, and tremendous concerns about the increasing resistance to antibiotics and restraining costs. Most prescriptions of antibiotics in low-risk outpatients with CAP are empirical and there are several reasons for this.

First, the identification of pneumonia among lower respiratory tract infections (LRTI) in outpatients is not an easy task. The diagnosis is currently based on the occurrence of fever, rhonchi and infiltrates on the chest X-ray. It is considered for any patient with features of severe illness or who has new focal chest signs. It may also be clinically appropriate to perform a chest- $X$ ray in those patients with LRTI who fail to respond to initial antibiotic treatment, show clinical deterioration or develop complications. However, there is evidence that history and medical examination together may correlate better with a CT scan than with a chest X-ray. The frequency of focal shadows on a chest $\mathrm{X}$-ray in prospective studies of adults

\begin{tabular}{ll}
\hline KARGER & ( 1999 S. Karger AG, Basel \\
Fax +4161306 12 34 & 0025-7931/99/0665-0398\$17.50/0 \\
$\begin{array}{l}\text { E-Mail karger@karger.ch } \\
\text { www.karger.com }\end{array}$ & Accessible online at: \\
http://BioMedNet.com/karger
\end{tabular}

with LRTI varies from 2 to $57 \%$ of patients, the higher figures being found in more severely ill patients; whether the information gained from the chest X-ray adds to the clinical picture and management remains unknown. In fact, a chest X-ray is likely to be of value in only a minority of patients with LRTI in a community setting.

Second, no etiological diagnosis is usually obtained. Even when using the most invasive and sophisticated microbiological techniques, no pathogen is identified in about half of all episodes of pneumonia. To identify pathogens, it is necessary to investigate various types of microbiological samples which may not accurately reflect the infectious process. The result should be immediately available to the physician but this is obviously not the case since most samples are sent to a specialized laboratory, and the associated delay severely impairs the therapeutic impact of the investigation. Sputum is the most readily available sample for microbiological examination in patients with LRTI, but interpretation of the results should be performed with care because of the potential confusing effects of sample quality, delays in processing and prior antibiotic therapy. Most general practitioners are not equipped to perform blood cultures and the yield of positive blood cultures is usually low in outpatients at home. In most cases serological tests for 'atypical' pathogens are positive 2-3 weeks after the onset of disease, usually too late to influence therapy. Therefore, it rarely happens that clinical, radiological and/or microbiological evaluations lead to the diagnosis of pneumonia due to extracellular bacteria ('typical' pneumonia) or to intracellular bacteria ('atypical' pneumonia), which should be treated with different antibiotics.
Prof. Gérard Huchon

Service de Pneumologie, Hôpital Ambroise Paré

9 Avenue Charles de Gaulle

F-92104 Boulogne Cédex (France)

Tel. +33 149095802, Fax +33149095806 
Third, increasing resistance to antibiotics is an additional concern. There is plenty of evidence that overall resistance to antibiotics increases in some areas and this increase is likely related to the overprescription of antibiotics. Nevertheless, there is still no convincing evidence that resistance to antibiotics in the community setting is associated with an increase in mortality.

Last, but not least, the economical pressure leads to the question of the rationale for all investigations and for all antibiotic prescriptions. Any prescription will have to be balanced against its cost and therapeutic impact.

Therefore the study of Rovira et al. suggests that in low-risk patients with pneumonia managed in the community, there is clearly no need either for sophisticated investigations or association of antibiotics, and if an antibiotic is to be prescribed a macrolide such as clarithromycin seems to be a reasonable choice.

\section{References}

1 Rovira E, Martinez-Moragon E, Belda A, Gonzalvo F, Ripolles F, Pascual JM: Treatment of community-acquired pneumonia in outpatients: A randomized study of clarithromycin alone versus clarithromycin and cefuroxime. Respiration 1999;66:413-418.

2 Huchon GJ, Gialdroni-Grassi G, Léophonte P, Manresa F, Schaberg T, Woodhead M: Initial antibiotic therapy for lower respiratory tract infection in the community: A European survey. Eur Respir J 1996;9:1590-1595.

3 Woodhead M, Gialdroni-Grassi G, Huchon GJ, Léophonte P, Manresa F, Schaberg T: Use of investigations in lower respiratory tract infection in the community: A European survey. Eur Respir J 1996;9:1596-1600.

4 Huchon G, Woodhead M, Gialdroni-Grassi G, Léophonte P, Manresa F, Schaberg T, Torres A, Didier A, Dorca J, El Ebiary M, Roche N: Guidelines for management of adult community-acquired lower respiratory tract infections. Eur Respir J 1998;11:986-991.

5 Huchon G, Woodhead M, Gialdroni-Grassi G, Léophonte P, Manresa F, Schaberg T, Torres A, Didier A, Dorca J, El Ebiary M, Roche N: Management of adult community-acquired lower respiratory tract infections. Eur Respir J 1998;57:281-316. 